\title{
"Los jóvenes son el futuro": Prácticas de la juventud en la participación política durante la primera ronda del proceso de elecciones 2018 en Costa Rica
}

Recibido: 30 de junio de 2020

Revisado: 22 de agosto de 2020

Aprobado: 20 de setiembre de 2020

Mario Alberto Araya Pérez

Costarricense. Licenciado en

Antropología Social por la

Universidad de Costa Rica.

Actualmente es investigador en el

Centro Agenda Joven de la

Universidad de Estatal a Distancia

(Costa Rica). Docente en la

Universidad Autónoma de

Monterrey (Costa Rica). Correo

electrónico: marayap@uned.ac.cr

ORCID: 0000 0002 6658 9757.

Natasha Alpízar Lobo Costarricense. Máster en Antropología por la Universidad de Costa Rica. Actualmente es docente en las escuelas de Antropología y de Ciencias Políticas de la Universidad de Costa Rica (Costa Rica). Ha trabajado en diversos procesos de investigación dentro de Agenda Joven en la Universidad Estatal a Distancia (Costa Rica). Correo elctrónico: natasha.alpizar@ucr.ac.cr ORCID: 0000 0001 9846 0643.

Adam Álvarez Calderón Costarricense. Licenciado en Antropología Social por la Universidad de Costa Rica. En la actualidad, es coordinador de proyectos en el Servicio Jesuita para Migrantes Costa Rica. Correo elctrónico: adam.alvz@gmail.com

ORCID: 0000 0003 2375 2902.

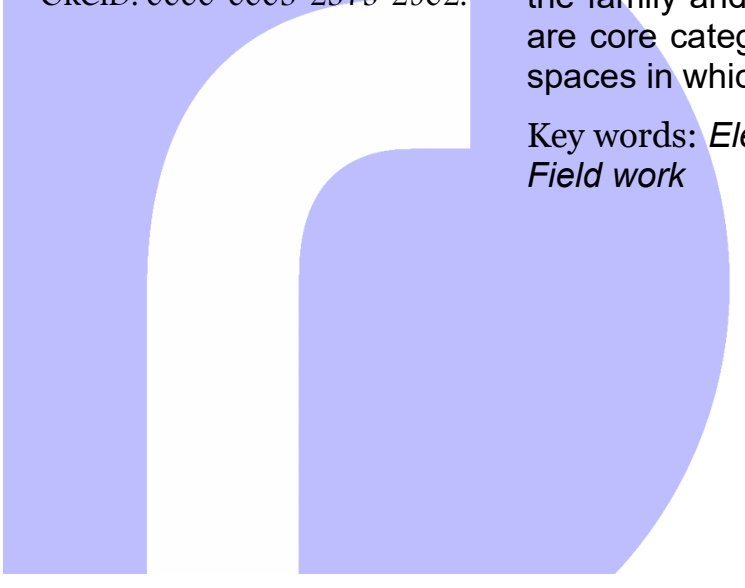

https://revistas.uned.ac.cr/index.php/rupturas (c) (1) (3) (-) Field work
Resumen: La imagen "los jóvenes son el futuro" es empleada habitualmente en el ámbito de la participación política para designar a una supuesta grupalidad considerada a partir de criterios etarios. A partir de la investigación aquí presentada, basada en una observación participante en dos cantones costarricenses durante la primera ronda de las elecciones 2018, se pudo demostrar que dicha imagen es negociada, atribuida y asumida de forma relacional en entornos diferenciados. En otras palabras, no existe un entorno previo de participación política en el cual las personas consideradas jóvenes decidan o no involucrarse; por el contrario, este emerge y muta a lo largo de la campaña política. En el proceso, el ambiente electoral, la familia y la constitución de la imagen de las personas jóvenes en las prácticas son categorías medulares al analizar el involucramiento de esta población en los espacios en que se desenvuelven.

Palabras clave: elecciones; participación política; participación juvenil; antropología; trabajo de campo

\section{"Young People are the Future": Youth Practices in Political Participation During the First Round of the 2018 Election Process in Costa Rica}

Abstract: The image "young people are the future" is usually used in the field of political participation to designate a supposed group based on age criteria. The research herein is based on participant observation in two Costa Rican cantons during the first round of the 2018 elections; it was possible to demonstrate that this image is negotiated, attributed and assumed in a relational manner in differentiated environments. In other words, there is no prior environment for political participation in which people considered young decide or not to get involve; on the contrary, it emerges and mutates throughout the political campaign. In the process, the electoral environment; the family and the constitution of the image of young people in the practices, are core categories when analyzing the involvement of this population in the spaces in which they operate.

Key words: Elections; Political participation; Youth participation; Anthropology; 
1. Información publicada en el Tribunal Supremo de Elecciones, "TSE da a conocer padrón nacional electoral definitivo", publicado en https://www.tse.go.cr/comunica do624.htm

\section{Introducción}

"Contrario al pensamiento que equipara a los jóvenes como el futuro, los jóvenes son una parte de la población de singular relevancia en torno al presente del debate político y a las nuevas formas de organización de los partidos" (Treminio y Pignataro 2015, 33). La cita anterior refleja una posición alternativa común frente a una idea que se ha generalizado en los escenarios de participación política electoral en Costa Rica: los jóvenes son el futuro. Esta expresión es común encontrarla en la televisión, periódicos, declaraciones de representantes políticos o conversaciones en general durante las elecciones.

Contrario a lo que pueda pensarse, los jóvenes como futuro no es una imagen que emerge de algo que pueda denominarse "mundo adulto", entendido muchas veces como un grupo etario por encima de los 35 años, para dejar fuera de juego a un sector significativo de la población de menor edad del ámbito de la política, más del $40 \%$ del padrón electoral del país ${ }^{1}$. Pero entonces, ¿qué quiere decir "los jóvenes son el futuro", en términos de la participación política durante el proceso de campaña electoral?

El 4 de febrero del 2018 se llevó a cabo la primera ronda del proceso electoral para elegir una nueva Asamblea Legislativa y al presidente de la República, lo cual marcó el final de la primera etapa de un proceso de campaña política que inició desde octubre del año anterior. La opinión pública la catalogó como marcada por el desencanto y el fervor religioso (Murillo 2018a; Murillo 2018b). Pese a ello, el día de las elecciones estuvo marcado por un cierto sentimiento de expectativa festiva, de gran presencia y movilidad de personas, incluidas, por supuesto, las personas jóvenes (González, Bermúdez y Astorga 2018).

Es en este contexto en el cual recuperamos un extracto de diario de campo, el cual refleja la latencia de esta noción de jóvenes como futuro en función de su papel de participación política. Este corresponde a una conversación con una mujer de 22 años, colaboradora de uno de los partidos políticos de la contienda, quien se refiere a su percepción respecto a la expectativa del papel de los jóvenes en la política:

Entonces siento que esa mentalidad de nosotros los jóvenes va a ser algo que va a ayudar a Costa Rica en un futuro. Que todavía nos hace falta un poquito para verlo, que las generaciones jóvenes seguimos jóvenes, pero igual se puede influenciar, igual se puede ir haciendo el 
cambio (Observador 1, comunicación personal, 4 de febrero del 2018). ${ }^{2}$

2. A lo largo del artículo, esta será la manera de citar los extractos de las observaciones realizadas durante del trabajo de campo. Se distinguirá entre "Observador 1" y "Observador 2" para diferenciar al investigador y el lugar donde se hizo el registro. En el primer caso, en el cantón de Santo Domingo y en el segundo, en el cantón de Montes de Oca. En la sección de metodología se profundizará un poco más lo anterior. mental, las ideas y no en las acciones concretas ni directas del suj Tercero, la proyección hacia el futuro, lo cual representa una negación de un posible aporte en el presente.

Todo esto conlleva que "lo joven" es una condición del presente a la que le está negada la posibilidad de acción, la cual puede generar su aporte solo a través de la influencia vinculada a una supuesta mentalidad beneficiosa que le posibilita un protagonismo futuro y, a la vez, asegura a ciertos sujetos protagonizar el presente, tomar decisiones, ejecutar acciones. Visto de esta forma, pareciera que ciertos sectores de la población, considerados en términos etarios, han asumido la imagen de que los jóvenes son el futuro, cuya construcción muchas veces es atribuida a los adultos y no a procesos relacionales.

En términos generales, a nivel de investigaciones hay una gran preocupación por el tema de la participación política en general, pero poca especificación en cuanto a la población joven, esto según una revisión sistemática de literatura científica e indexada sobre comportamiento político y juventud realizada por González-Sancho (2017) en Latinoamérica y España. De acuerdo con el autor, los estudios muestran que ha habido grandes esfuerzos institucionales por desarrollar programas que propicien que la la población joven participe, pese a ello sigue habiendo una sensación de lejanía y desvinculación de las personas respecto a la política.

Siguiendo a González-Sancho (2017), la participación se ha considerado en los estudios sobre todo en términos formales y en relación con lo electoral. Se ha evidenciado que se vincula con el goce de ciertas condiciones socioeconómicas y educativas que promueven la integración de las personas ${ }^{3}$. Lo anterior, junto con percepciones de corrupción y poca confianza en el sistema político, hace que tanto las personas adultas como jóvenes no tengan, en proporciones similares, deseo de participar en política formal.

Fuera de la revisión del autor anteriormente señalado, en Costa Rica se encuentran algunas reflexiones sobre la forma como las personas jóvenes se relacionan con la política electoral y su participación. Treminio y Pignataro (2015) sugieren que el comportamiento electoral y la manera de pensar la política de las personas jóvenes (18-35 años) difieren de las no-jóvenes (más de 35 años); se rescata que, según los datos del Tribunal Supremo de Elec-
3. Esto coincide con otra de las investigaciones realizadas en el OPEJ (2018), enfocada en entrevistas a personas jóvenes candidatas a puestos de elección popular, en las cuales se evidenciaban los componentes social, familiar y educativo en la integración en procesos de participación política formal. 
ciones (TSE), las primeras se abstienen de votar en mayor medida que las segundas. Sin embargo, cabe resaltar que para el único elemento analizado en el cual además de la edad se hace un análisis en función de otras variables, como el nivel económico, deja de ser un elemento explicativo respecto a las diferencias observadas en ambos grupos. Pese a ello concluyen que la población joven, en tanto grupo demográfico, es relevante para la ciencia política.

Aunado a esto, algunos autores han señalado que la mejor forma de asegurar una mayor y mejor participación de las personas jóvenes en aspectos políticos es a través de elementos como la educación y la creación de espacios exclusivos para esta población, alegando un supuesto desconocimiento del sistema político, lo cual genera desconfianza y apatía hacia la participación (Alvarado Chaves 2014). No obstante, en otras investigaciones se ha demostrado que no necesariamente existe una desvinculación ni desconocimiento de las personas jóvenes hacia la política, sino con algunos de sus aspectos formales. Por el contrario, ciertos sectores juveniles tienden a mostrarse más críticos y a participar de otras formas más allá del voto. Además, señalan que cuando hay espacios que pueden incluir a personas jóvenes, se les toma menos en cuenta; inclusive, en espacios para esta población -partidos políticos $\mathrm{u}$ otras estructuras formales - los intereses reproducidos no se asocian a "lo joven", sino a una lógica adultocéntrica (Segura Arias 2013; Treminio y Pignataro 2015; González Sancho y Henríquez Cáceres 2016).

En relación con esta y otras problemáticas, desde el año 2010, el Centro Agenda Joven de la Universidad Estatal a Distancia (UNED) se ha planteado identificar las prácticas políticas que caracterizan el comportamiento electoral de las personas jóvenes a través de la investigación del Observatorio Político Electoral Juvenil (OPEJ). Esto durante las campañas políticas, tanto municipales como presidenciales. Una de las preocupaciones recurrentes desde el inicio ha sido la imagen de la persona joven en dichos procesos $\mathrm{y}$, recientemente, comprender de mejor forma cómo se constituye y su relación con las formas de participación.

Hasta ahora, se han logrado precisar algunos aspectos sobre esta imagen. Por ejemplo, la "juventud" ha sido vista como el cambio, pero incapaz de tomar decisiones según las personas adultas de los partidos. Además, que es percibida como objeto de acciones asistenciales y no como protagonistas de sus realidades (OPEJ 2013). Se suelen considerar sus características positivas, aunque no se le reconoce como participante activo o vinculante, más allá de su colaboración en actividades proselitistas (OPEJ 2014). En aquellas ocasiones en las que se les considera capaces tomar decisiones, se enfatiza en la inexperiencia, la falta de madurez y responsabilidad en cuanto a temas relevantes. Se relega su campo de acción a ámbitos como el deporte, la recreación, la educación y el trabajo (OPEJ 2016).

Frente a este panorama, nos planteamos las siguientes interrogantes. En términos de la participación política electoral, tanto durante el proceso de campaña política como el día de las elecciones, ¿qué prácticas distinguen las for- 
mas de participación de las personas jóvenes durante el proceso? ¿Cómo pueden entenderse dichas prácticas en función del entorno en el cual se desenvuelven? ¿Qué propiedades de este entorno motivan sus formas específicas de participación?

Para dar respuesta a estas interrogantes, el documento se divide en seis apartados. El primero corresponde a la presente introducción en el que se problematiza el objeto de estudio, a saber, las prácticas de la juventud en la participación política electoral, en sus dimensiones de problema social y problema de investigación. En el segundo, se presenta el sustento teórico-metodológico que, desde el punto de vista de la antropología, posibilitó recolectar la información y la construcción de las categorías que se presentan como resultados. En el tercero, se exponen los resultados de la primera categoría analítica relacionada al ambiente electoral, es decir, al entorno de relaciones que convoca las prácticas de la juventud en relación con el proceso electoral, el cual está pautado por dimensiones de espacio y tiempo.

En el cuarto, se muestran los resultados de la segunda categoría relativa a la familia como un componente esencial en el entramado de relaciones que orienta la participación política de las personas jóvenes, lo cual desdibuja la idea de los jóvenes como grupo autorreferencial, en sus formas de participación presentes en las discusiones sobre cultura política juvenil. En el quinto, se ofrecen los resultados de la tercera y última categoría relativa a la imagen de las personas jóvenes en las prácticas, es decir, el lugar en que las ideas sobre las personas jóvenes se encuentran con las condiciones de posibilidad para expresarse en términos prácticos. Finalmente, en el sexto se presenta, a modo de conclusiones generales, la discusión que arrojan los resultados de las categorías en función a la problemática de investigación descrita en la introducción, en diálogo con otras producciones en este campo de la participación política juvenil.

\section{Apartado teórico-metodológico}

\section{Sobre las nociones conceptuales}

Para contextualizar el aporte de este artículo, es necesario considerar que esta reflexión surge de un esfuerzo de investigación más amplio del OPEJ en Agenda Joven, al cual se hizo referencia al inicio del documento. Para el 2018, dicho proceso de investigación desplegó una metodología mixta en la que se incluye una encuesta a nivel nacional a personas jóvenes de entre 18 y 35 años, entrevistas en profundidad a personas jóvenes candidatas a puestos de elección popular, un análisis de contenido de los Planes de Gobierno y ejercicios de observación participante en dos cantones de la Gran Área Metropolitana costarricense (GAM). 
4. No se contempla la Tercera Encuesta Nacional de Juventud dado que, a la fecha, no se cuenta con un informe final de esta en la página del Consejo de la Persona Joven, solo un informe parcial, en el que no se cruza la participación en grupos en términos generales para la totalidad de las personas encuestadas.
Un punto de partida conceptual de todas las líneas de trabajo del OPEJ se relaciona con la "participación política". Esta puede entenderse como todos aquellos elementos propios de una sociedad, tanto a nivel individual como colectivo, dirigidos a la explicación, demanda, influencia o toma de posesión en los procesos de decisión política (De Mantilla Fernandez 1999). Asimismo, la participación propiamente electoral se da en tiempos de campaña, incluye la votación y el abstencionismo, pero no se limita a estas dos, ya que hay otras formas posibles de participar activamente.

Dicho esto, se esperaba determinar desde el punto de vista de la antropología la contribución en términos de comprensión de la participación política de las personas jóvenes más allá de los espacios tradicionalmente considerados, por ejemplo, los partidos políticos. De manera que, a través de la observación participante, se priorizó el entorno de las personas en distintos lugares, horarios y dinámicas particulares a nivel cantonal.

La decisión de no trabajar únicamente con los partidos políticos se basa en la Segunda Encuesta Nacional de Juventud (2013). ${ }^{4}$ Esta determinó que la participación de las personas jóvenes en estructuras políticas es mínima, apenas el 3,4\% señaló ser parte de un partido político, mientras que el 31,2\% participa en grupos religiosos y el $29,4 \%$ en grupos deportivos. Lo cual coincide con la encuesta realizada para el OPEJ (2018), en que el $90 \%$ de las personas jóvenes señalaron no haber participado en partidos políticos en los últimos cinco años.

Esto conduce a pensar, según Treminio y Pignataro (2015), que si las diferencias en participación sobre el ejercicio del voto entre personas jóvenes y no jóvenes es mínima, su comprensión entonces debe ubicarse no en espacios formales (partidos políticos), sino en lugares particulares en espacio y tiempo (Ingold 2015c). Por lo tanto, nos llevó a centrar nuestra experiencia en los entornos donde las personas se desenvuelven. Bajo esta lógica, podemos entender a las personas jóvenes como proceso, es decir, como colectivos de personas en constante formación, lo cual se da en lugares relacionales, donde están involucradas distintas personas (jóvenes y no jóvenes).

Esto nos aleja de las aproximaciones que consideran a las personas jóvenes como un grupo etario particular y que debe ser entendido en sus propios términos. Así, el trabajo no estaría enfocado en desentrañar una suerte de "cultura política" que determina el comportamiento de las personas, sino más bien las condiciones de posibilidad que tienen para participar en procesos de decisión política. Autores como Carrithers (1995), Ingold (2015a, 2015c) y Latour (2008) colocan en primer lugar las posibilidades de hacer de las personas, antes de dar por sentado aquello que se debe explicar (cultura, sociedad, participación).

Además, nos valemos de formas de interpretación de la juventud, las cuales sugieren que ser joven y sus implicaciones no pueden entenderse desde aspectos etarios, ni a partir de las cargas valorativas propias de las expectativas que un colectivo social deposita sobre un determinado grupo de perso- 
nas; deben entenderse desde las prácticas de la juventud, esta noción teórica propone que "la serie de relaciones sociales que se caracterizan como 'joven' nace de la interacción entre sujetos en el entramado social, en el que se mezclan las ideas sobre las personas jóvenes con las condiciones de posibilidad que este grupo poblacional tiene para expresarse" (Zúñiga Núñez 2016, $6)$.

Por todo lo mencionado, consideramos que la condición de joven o juventud es de carácter relacional, no es intrínseca ni inherente a una persona o grupo de personas en particular; se atribuye en determinados contextos en función de las prácticas desarrolladas, ya sean manifiestas o supuestas. Lo anterior implica que, para este trabajo, no nos enfocamos en una población legalmente definida como joven en términos etarios como lo establece la Ley General de la Persona Joven $\mathrm{N}^{\circ}$ 8261, sino que, por el contrario, trabajamos con un grupo amplio de personas de muy distintas edades constituyentes de un entorno particular, para observar cómo en dichas interacciones aparece la imagen de lo joven y las condiciones de posibilidad para que esta se exprese en términos de participación política en un contexto electoral.

\section{Sobre las nociones metodológicas}

Es necesario señalar que la observación participante estuvo a cargo de un equipo de personas formadas en antropología, por lo que es destacable un punto relacionado con el momento y lugar de observación. A diferencia de otras ediciones del OPEJ, en esta ocasión la observación no se dio únicamente el día de las elecciones, en recintos de votación y zonas aledañas, sino que se extendió durante dos meses antes del día de las elecciones. Esto para entender la participación política electoral juvenil como un proceso que tiene como hito fundamental el momento de ejercicio del voto, pero no se restringe a este.

Ello implica que la observación participante realizada no es aquella tradicionalmente asociada a la etnografía que, por definición, corresponde a la descripción de la cultura y escritura de formas de grupos determinados (Ingold 2015b, 2017). Antes bien, en este caso, la observación misma se ejecutó como un proceso de correspondencia con ese entorno -lugar- en emergencia (Ingold 2015c). De acuerdo con Díaz de Rada (2012) y Téllez (2007), la observación participante se caracteriza por la presencia física y directa de quien investiga, por su interacción con diversos actores, prácticas y el entorno que se desea estudiar, lo cual implica ver, sentir, hablar y escuchar con múltiples actores en diferentes entornos. Es importante insistir que en el trabajo de campo no se buscó comprender la participación política juvenil en partidos políticos.

Para este caso en particular, la observación se llevó a cabo en dos cantones: Montes de Oca, en la provincia de San José, y Santo Domingo, en la provincia de Heredia. ${ }^{5}$ Existen dos razones que motivaron esta selección: la primera, por viabilidad de la investigación en cuanto a la accesibilidad y los recur-
5. En investigaciones anteriores realizadas por el OPEJ, las observaciones se han hecho únicamente en los días de elecciones, en los 14 cantones de mayor y menor participación según los votos de las personas entre los 18 y 35 años, distribuidos en las siete provincias de Costa Rica. En esta circunstancia hay una excepción, en tanto la investigación se concentró solo en dos cantones de la Gran Área Metropolitana (GAM). 
6. Se omiten en este artículo nombres particulares de personas, empresas, locales comerciales y partidos políticos con el fin de guardar confidencialidad de la información recolectada, pero también porque brindarla no posee ningún sentido analítico de fondo. sos disponibles en el momento; la segunda, por las similitudes y diferencias de ambos cantones, lo que permite su comparación.

Por un lado, tanto Montes de Oca como Santo Domingo han tenido históricamente la mayor participación juvenil en votos desde el 2010, año en que se implementó por primera vez la investigación del OPEJ. Por otro, los dos cantones poseen actividades disímiles en el ámbito cultural, socioeconómico y residencial. En Montes de Oca, se encuentran las principales universidades del país y el uso del suelo es mucho más comercial en comparación con Santo Domingo, en donde la dinámica está más inclinada hacia lo habitacional.

Fuera de lo mencionado, las observaciones se inscriben en un lapso de dos meses, iniciaron el 6 de diciembre del 2017 y finalizaron el 4 de febrero del 2018. Se tomaron en cuenta diversos días -entre semana y fines de semana- y horarios - mañana, tarde y noche-. También se visitaron múltiples lugares a conveniencia de las personas observadoras según tiempo, condiciones climáticas y posibilidades de movilización; por ejemplo, se frecuentaron calles, avenidas, transportes públicos, parques, ferias, centros y locales comerciales, casas club de partidos políticos y actividades proselitistas - piquetes, volanteos, centros de votación el día de las elecciones-. ${ }^{6}$ En total, se obtuvieron 19 registros de observación, diez en el cantón de Montes de Oca y nueve en el cantón de Santo Domingo- que corresponden a más de 200 páginas escritas.

Para efectos del proceso de recolección de datos y análisis, fueron fundamentales las reuniones de manera constante por parte del equipo investigador. Una vez escritas las observaciones, se procedió a releerlas y empezar a categorizar la información en colectivo. Los hallazgos más relevantes fueron discutidos dentro del equipo de Agenda Joven.

\section{Ambiente electoral}

Esta categoría nos permite contextualizar, en términos generales, las formas en que las personas percibieron e hicieron referencia al desarrollo del proceso electoral en los dos cantones donde se realizó la observación. Dado que se estuvo en campo durante más de dos meses, se registró cómo se transformaban los entornos a partir de las dinámicas de participación.

De manera central, destaca una relación ausencia-lejanía que se corresponde con temporalidades y espacios diferenciados. Mientras más lejos el día de la elección - diciembre y las tres primeras semanas de enero-menor fue la presencia en el espacio público de signos externos de los partidos políticos y de actividades colectivas de participación. Los pocos signos observados, se ubicaron en las áreas centrales de ambos cantones, lo mismo que las escasas actividades realizadas (volanteos, piquetes, debates, etc.). 
Conforme se acercó el día de la elección —última semana de enero- hubo cambios en los dos cantones, con acciones que buscaron mostrar un ambiente más festivo o con mayor participación de la registrada en las semanas previas. Finalmente, fue el propio día de la elección el que tuvo mayor movimiento de personas, recursos y actos con la intención de promover y asegurar el voto.

\section{Un proceso apagado}

En las observaciones hechas en ambos cantones fue constante una caracterización del ambiente electoral como "apagado". Las personas utilizaron ese calificativo para describir cómo sentían y vivían lo que estaba pasando en sus localidades, donde predominó un reducido despliegue publicitario y uso del espacio público para actividades proselitistas.

Durante el mes de diciembre y casi la totalidad de enero prevalecieron prácticamente los mismos signos externos - vallas publicitarias, banderas en algunas casas y clubes de los partidos-, en los mismos sitios (centros de los cantones). En la poca publicidad que se observó, no aparecían personas jóvenes y cuando lo hacían era como un elemento decorativo, es decir, una población más entre otras. Las vallas publicitarias vistas en ambos cantones presentaban imágenes de personas adultas, eslóganes o frases con promesas de campaña.

Asimismo, las personas jóvenes no estaban en el espacio público haciendo actividades relacionadas con el proceso electoral. En Santo Domingo, fue prácticamente nula la presencia vinculada a partidos políticos o a alguna acción electoral. En Montes de Oca, fue más común sostener conversaciones e incluso asistir a actividades organizadas o donde participaban jóvenes.

A pesar de esta diferencia entre cantones, la tónica fue que quienes tenían alguna participación formaban parte de los grupos de juventud de los partidos. Esto fue más claro en Montes de Oca, donde se realizaron volanteos y algunos piquetes de militantes. Además, otras actividades externas a los grupos políticos, como un debate organizado por una plataforma de colectivos con participación juvenil, presentado como un debate de jóvenes para jóvenes y que reunió a 10 de los 13 aspirantes a la presidencia.

Con las excepciones de las actividades realizadas en Montes de Oca, posibles de explicar en buena parte por la mayor politización que predomina debido a los accesos educativos, económicos y sociales, la ausencia de calidez o falta de entusiasmo es una característica importante de la vivencia del proceso electoral en ambos cantones.

No solo hay menos movimiento y participación en las calles cuanto más lejos el día de la elección, sino que las personas recordaban como apreciación dominante que, en un tiempo pasado, todo era más festivo, tal como destaca un hombre adulto en una de las situaciones representativas del conjunto de observaciones: 
Directamente le pregunté [a Don Jose] cómo sentía el clima electoral en el cantón, a lo que respondió que "muy frío", "sin ánimo", "como muy muerto". Me dice que él recuerda otras campañas donde había más movimiento y "color" en la calle, gente que ponía banderas en sus casas, y señalando con su dedo la calle, me indica: "vea, ahora no se ve nada de eso por ninguna parte". Don Jose cree que eso se debe a que la gente está "muy cansada de los mismos cuentos" y que "ya nadie tiene ganas de hacer nada para elecciones", pues "eso no paga" (Observador 2, comunicación personal, 18 de diciembre del 2017).

Con independencia del desinterés que las personas puedan tener con la política electoral representativa, uno de los posibles factores para explicar la ausencia de participación en el espacio público, en ambos cantones las personas justificaban que no hubiese tanto movimiento en la calle debido al traslado de la actividad electoral a otro espacio. Para las personas, ahora todo se concentraba en las redes sociales.

De algún modo, esto se visualiza en el hecho de que, aun cuando en ambos cantones había clubes de los partidos políticos, las personas no sabían referenciar dónde se ubicaban esos espacios, decían no conocerlos, incluso afirmaban su inexistencia. A esto, se une un desconocimiento de las candidaturas electorales jóvenes que no eran identificadas.

\section{Es difícil atraer a los jóvenes}

Uno de los aspectos más sobresalientes de las observaciones efectuadas en ambos cantones es la justificación, desde los partidos políticos, de la dificultad que tenían para involucrar a las personas jóvenes. Apuntaban a los esfuerzos para lograr integrar a esta población en las estructuras partidarias y, en particular, en el desarrollo del proceso electoral, pero no obtenían buena respuesta, tal como lo indica Don Pedro en una conversación, un hombre adulto, representante local de un partido político

"Muchos jóvenes en Costa Rica son muy vagos, como que nada les interesa, ya no se involucran como en el tiempo de uno que sí buscábamos cómo prosperar". Don

Pedro considera que se ofrecen posibilidades de partici- 
pación a las personas jóvenes, pero "no siempre las aprovechan" (Observador 2, comunicación personal, 17 de enero del 2018).

De algún modo, se deposita la responsabilidad por la no participación en las personas jóvenes, por su desidia o deseo de no involucrarse en política electoral representativa, no en las medidas emprendidas por los partidos políticos que, sobre todo, se restringían al plano de lo formal. Cuando se conversó con representantes y personas jóvenes militantes de los partidos políticos de ambos cantones sobre las actividades que estaba haciendo esta población, las respuestas, en general, remitían a actividades como volanteos, piquetes y otras acciones de voluntariado y agitación, es decir, situaciones con poco protagonismo o responsabilidad en la toma de decisiones, tal como lo apunta una de las militantes:

—Pues aquí yo vengo y abro y me quedo todo el día. A veces la gente viene para pedir calcomanías, banderas, información; también vienen a dejar cosas del partido o hacen reuniones, sí.

—Como qué tipo de gente viene a pedir de eso...

-Sobre todo gente ya mayores. Llegan a pedir calcomanías y banderas, pero quién sabe en donde las ponen porque no se ven por ningún lado.

-Ah ok. ¿Y las de personas jóvenes participan en lo que usted me dice o en otras cosas dentro del partido?

—Bueno, los jóvenes están más como voluntariado, sí, repartiendo volantes, banderas... Pero no participan mucho, es muy baja la participación, nos ha costado muchísimo llamar a la población joven, sobre todo para el voluntariado, sí. Hay grupos de jóvenes en el partido, pero es muy poco.

—Ah ok. ¿Y en otras cosas, como en puestos de decisión hay personas jóvenes? 
-Sí, claro, tenemos una diputación por el tercer lugar, Paola Sánchez. Hay puestos de delegados también... El partido lo exige — no menciona nombres- (Observador 1, comunicación personal, 12 enero del 2018).

A esta participación, centrada en la animación de las personas jóvenes dentro de las estructuras locales de los partidos políticos, se une una dificultad o resistencia a hablar fluidamente del tema político electoral. Las conversaciones que se lograron mantener durante el proceso de observación ocurrieron no por un interés genuino y entusiasta de hablar sobre la campaña. Esto no implica necesariamente apatía, pues buena parte de las personas con las que se interactuó no eran ajenas ni desconocían propuestas y acciones de los partidos, pero no expresaban mayor pasión al respecto.

\section{Calentar un poco el ambiente}

En la semana previa al día de la elección, en los dos cantones ocurrieron situaciones atípicas respecto a las tendencias que se habían registrado durante los casi dos meses previos de estar realizando observación. Santo Domingo se llenó de publicidad —en el centro y en zonas periféricas- y Montes de Oca tuvo una importante reunión de personas de varios partidos políticos en la Fuente de la Hispanidad en la víspera del 4 de febrero.

Las personas dieron cuenta de estos hechos como una forma de visibilizarse a último minuto, justo cuando el acto de ejercer el voto estaba más próximo:

- ¿Cómo cree usted que ha respondido la gente con la publicidad?

-Mirá, es que a veces la gente ve una valla o ve banderas, pero las ve y listo -hace un gesto con la mano-. $\mathrm{O}$ sea, uno lo hace como prender más el ambiente y todo del partido, pero yo creo que eso, di, no influye tanto, es como para que la gente vea que uno está presente, pero yo creo que una valla no decide mucho, yo creo que sí los debates, una valla no va a tener mucha, como mucha decisión verdad... (Observador 1, comunicación personal, 25 de enero del 2018).

También como una manera de "calentar" el ambiente que, como se ha indicado, constantemente se había considerado como "apagado". Un extracto de la 
conversación sostenida con una señora y un joven, integrantes de un partido político, lo pone de relieve:

"Esta vez no se ha hecho mucho en las calles, hasta ayer yo creo", ríe.

Un muchacho del partido, que parece funge como guía, se integra a la conversación y dice que "ayer, en la rotonda de la Hispanidad se dio la concentración más llamativa de todo el proceso que he visto", "a pesar de que no era permitido", agrega la señora, continúa:

"Porque no se podía hacer nada por la tregua, sin embargo, aunque había miembros del Tribunal, decidieron, tal vez por la frialdad que había habido y todo ese asunto, permitir, y porque no habían problemas, la gente, a pesar de la mucha diversidad de partidos, estaban como muy tranquilos y disfrutando y todo, entonces quisieron como dejarlos para calentar un poco el ambiente, pero sí se brincaron ahí unas normas, porque de hecho si hubiera sido permitido desde el inicio todos hubiéramos planeado caravanas o casas así".

El muchacho dice: "de hecho ayer mucha gente llegó, pero a título personal, no por el partido, sino porque quiero ir a demostrar que yo participo, fue como espontáneo de la gente". La señora recalca que "no era de partidos, que fue espontáneo, fue como que se armó la fiesta y todo el mundo empezó a llegar, pero supuestamente todo transcurrió en paz y tranquilo" (Observador 2, comunicación personal, 4 de febrero del 2018).

Llama la atención que estas acciones sean calificadas como espontáneas, como si se tratase de un ímpetu de participación que se manifiesta en las personas a último minuto: 
- La verdad, como te dije, yo aquí yo muy nueva, yo me apunté anoche porque se me metió el agua, "mae, yo a esto me apunto de fijo" entonces llegué a la casa y de una entré. Este, pero di, por ahora las responsabilidades, esta, es la primera (Observador 1, comunicación personal, 4 de febrero del 2018).

En una campaña electoral definida, como se ha visto, por un ambiente "apagado" y una participación restringida y escasa de las personas jóvenes, estos actos realizados al final son importantes porque permiten conocer parte del sentido que se le otorga al involucramiento político.

Se constata, a partir del conjunto de observaciones, es que no se prioriza, de parte de la mayoría de los actores involucrados, el trabajo e implicación en el proceso de vivencia y formación política, sino que las prácticas de participación siguen estando centradas en función de un acontecimiento: la elección.

\section{Familia y participación política}

Esta categoría está íntimamente vinculada con la anterior. La grupalidad de la familia, en el trabajo de observación, aparece y es mencionada por las personas con más frecuencia en los días próximos a la jornada electoral y la votación propiamente. Por el contrario, en los días más lejanos, la referencia a la familia es esporádica.

Dicho esto, dos escenarios generales se presentaron en esta categoría de participación política. Uno sobre la ruptura y continuidad respecto al abstencionismo o la apatía, el otro sobre las mismas o distintas preferencias partidarias. Es preciso, en este sentido, diferenciar lo anterior de lo que se ha denominado "tradición familiar" respecto al voto solo en términos de una preferencia hacia un mismo partido. En este caso, el nexo entre familia y participación política, por un lado, se relaciona con esa grupalidad que las personas señalaban como referente — tanto en el discurso como en las prácticas-; por otro, esta alusión responde más a una de las condiciones de posibilidad en la participación política, lo que no se traduce necesariamente en votar a favor o en contra de un partido político.

\section{Abstencionismo o apatía}

En días lejanos a las elecciones, específicamente en el mes de diciembre, dos situaciones dan cuenta del rol de la grupalidad familia cuando se trata de abstencionismo o apatía política. En la primera, la tutela y mandato de una persona adulta hacia una persona joven se puede ver en el siguiente extracto: 
A su hija de 19 años (que tiene la posibilidad de votar por primera vez) él le "advirtió" que no vote por nadie, porque no vale la pena darle el voto a ningún candidato, porque "ninguno hace nada". Le pregunté si su hija ha mostrado algún interés por participar en las elecciones a pesar de que él le diga que no tiene sentido. Respondió que no, que en su familia ya está muy claro que no se vota ni se involucran en nada electoral, y que, aunque su hija quisiera ir a votar, él no la dejaría porque, aunque sea mayor de edad él todavía es responsable de "guiarla" y hacerla ver qué es lo mejor para su vida, y él considera que votar es algo que no genera ningún aporte. Le dije que, si no consideraba que era su hija quien debía decidir si votar o no y, contundentemente, con un rostro serio, me dijo que "no", "eso no se discute" (Observador 2, comunicación personal, 12 de diciembre del 2017).

La familia, encabezada por un hombre adulto mayor, se convierte en un signo interesante para pensar en la participación política de las personas jóvenes, en la cual es este quien determina o marca la pauta. Si bien desde el extracto de la observación no se puede corroborar si en efecto la persona de 19 años cumple con el mandato o no, lo cierto es que a partir de la conversación con el hombre adulto hay una autorización de sí mismo sobre las decisiones de la hija. En esta relación de poder, el objetivo es dar continuidad a una apatía política dentro de la familia; de manera que el abstencionismo, lejos de ser un asunto individual es grupal — no conformado por grupos de pares-.

En la segunda situación, en la que se conversa con una mujer adulta nicaragüense, surgió el tema de las elecciones presidenciales y el abstencionismo:

- ¿Y usted ya sabe por quién votar?

—No, yo nunca he votado.

—¿Ajá? ¿Y eso por qué? 
—No, yo no voto. A mí, mi papá y mi mamá siempre me dijeron: "a usted ningún político le va a dar de comer ni le va a dar trabajo. Usted se va a tener que defender y mantener por usted misma". Mis papás nunca han votado y por eso yo nunca voté. Pero ahora las generaciones han cambiado. Mis dos hijos sí pasan metidos en todo [actividades políticas], en la escuela y el colegio. Ellos sí participan.

—Aah, ya veo... ¿Y tampoco allá en Nicaragua votó?

—No, nunca. Para votar aquí tengo que renunciar a mi país, tengo que nacionalizarme. $Y$ yo no quiero renunciar a mi país, nunca. Yo amo Nicaragua. Entonces no voto ni aquí ni allá. Ni sé quiénes están para votar (Observador 1, comunicación personal, 12 de diciembre del 2017).

En el extracto anterior, es posible dar cuenta de una relación un tanto más compleja entre continuidad y ruptura. Existe una continuidad de la mujer adulta respecto a su ascendencia, pero una ruptura en su descendencia. Es claro que la apatía política no se convierte en mandato a seguir para sus hijos en cuanto a participación política. Lo que en este caso ella identifica como "cambio".

\section{Preferencias en el voto}

Conforme el día de las elecciones presidenciales se aproximaba, la mención de la familia se convirtió en un elemento más visible. De ahí que, para esta tendencia, haya más situaciones específicas a las cuales aludir a la hora de presentar los datos. Por ejemplo, en varias observaciones se constató la participación política, en términos de ejercicio del voto por el mismo partido político o uno diferente, respecto a la preferencia del grupo familiar. En el siguiente extracto, se recupera una conversación con una mujer adulta acompañada por dos personas jóvenes:

Le consulto a la señora sobre las actividades que ha hecho [para el partido] durante la campaña en el cantón, y me dice que "casi no ha hecho nada", que "no recuerda si 
han hecho algo". La niña y el niño que acompañan a la señora, y que tienen 12 y 15 años, son sus sobrinos. Les pregunté si habían participado en alguna actividad del partido antes, y me dicen que no, que solo están apoyando a su tía el día de hoy porque ella se los pidió.

La señora me cuenta que en realidad ella vota y participa "por ser patriota" [...] Le pregunto por qué motivo apoya al candidato, y me dice que considera que de las opciones que hay es "el menos malo", además que parte de su familia se "metió a ayudar al partido, y que ella los siguió" (Observador 2, comunicación personal, 4 de febrero del 2018).

La primera impresión que deja el extracto es la manera en que las personas participan dentro de un partido político. Por un lado, se hace de manera muy puntual, es decir, no hay un proceso de involucramiento en diversos espacios, sino únicamente para el día de las elecciones. Por otro, la familia se vuelve referente para inclinarse hacia un mismo partido político, tanto en las personas jóvenes, quienes mencionan que estar ahí porque "ella [su tía] se los pidió", como en los adultos, en el caso de la mujer que "sigue" a su familia.

No obstante, como se estableció con anterioridad, algunas personas jóvenes se involucran y militan en partidos políticos que no necesariamente coinciden con las preferencias de otros familiares. Aun en estos escenarios, la grupalidad sigue teniendo peso y en algunos casos podría ser el "caldo de cultivo" para propiciarlo. Podemos identificarlo en una conversación con una mujer de 24 años:

— ¿Su familia la inspiró a usted también a estar aquí?

—Sí... Bueno, no, mi familia me inspiró a mí a estudiar

lo que estudio y seguir la carrera que elegí [...] enton-

ces yo ya tengo mi opinión al respecto. Yo tengo mi propio partido, entre todos nos apoyamos un montón y todo el asunto, pero cada quien tiene su propio partido. Es que, di, mi abuelo fue profesor de historia en la 
UCR, mi papá estuvo muchísimos años en la UCR, estuvo participando en cargos políticos allá, entonces toda la vida a mí me han fomentado mucho a que, número uno, la política es importante, hay que votar y es un tema que se tiene que hablar porque, di, es responsabilidad de todos los ticos, entonces ha sido más que todo gracias a mi familia. Entonces sí, mi familia me ha influenciado un montón (Observador 1, comunicación personal, 4 de febrero del 2018).

Si bien la mujer de 24 años participa en un partido distinto al de sus progenitores y al iniciar su respuesta titubea sobre si su propia familia le ha inspirado, conforme profundiza queda manifiesta la centralidad de esta grupalidad a la hora de reconocer su propio vínculo e involucramiento. Contrario a la primera situación, en este caso se puede entrever un proceso extendido de la persona joven con el ámbito más político-electoral.

Junto a todo lo anterior, sería justo señalar también las tensiones existentes entre las preferencias político-partidarias, iguales o distintas, y su relación a la grupalidad familia. En una visita a una casa club de un partido político, una mujer militante de aproximadamente 40 años menciona algunos detalles de su integración al partido político:

Ella se integró hace cuatro años pues su hermana la "convenció” de que debía involucrarse más, aunque es enfática en señalar que "siempre" ha votado por el partido "porque es el más decente que hay". Su hermana sí ha militado en el partido prácticamente desde su fundación, y a partir de ahí toda su familia le ha dado el apoyo al partido en todos los procesos electorales en que ha participado. Antes de votar por el partido actual, su familia acostumbraba a votar por otro partido [...] pero les "decepcionó la corrupción y la deriva que tuvo a favor de quienes más tienen y no de la mayoría" (Observador 2, comunicación personal, 17 de enero del 2018). 
Nótese la tensión entre el hecho de que la mujer fue "convencida" por un familiar y que al mismo tiempo haga hincapié en que siempre ha apoyado al partido político en cuestión. De igual manera, el cambio de preferencia de toda la familia a raíz de una sola persona, pero también consecuencia de un desencanto político. En otros escenarios, queda patente una contradicción: se menciona que no hay una referencia o se niega discursivamente la familia en cuanto a las filiaciones y la participación política, pero en términos fácticos está presente y jugando un rol muy activo. Esto último se ve en el siguiente diálogo:

—Nosotros hace como dos semanas porque dijimos "aquí hay que dar la pelea". Entonces nos apuntamos toda la familia.

— ¿Todos son familia?

—No. Ellos dos [son familia]. Y falta mi papá que anda en transporte y mi mamá preparando la comida y mi otro hermano que le anda ayudando.

—Ellos son una familia [señala a un grupo de personas dentro del toldo]. Estos son otra familia [señala a otro grupo de personas que están en el mismo toldo]. Hay otra familia. Y yo (Observador 1, comunicación personal, 4 de febrero del 2018).

Los últimos dos ejemplos indican que no siempre hay coincidencia entre lo que dice y lo que se hace. Pero inclusive dentro de los mismos discursos y prácticas, hay contradicciones y tensiones de diversos matices no del todo resueltas, tanto entre personas jóvenes como adultas, entre quienes reconocen abiertamente a la familia como un referente en su participación política y preferencia partidaria, y quienes no lo hacen. Más allá de esto, llama la atención que otro tipo de grupalidades - comunidad, barrio, amigos - no hayan tenido tanta presencia y protagonismo. De ahí parte el interés de dar relieve a esta categoría porque, como se constata, independientemente de cuán precisa o imprecisa sea su alusión, esta es un elemento latente bajo distintas formas, momentos y generaciones.

\section{Imagen de la persona joven en las prácticas}

Más allá de las diferencias y particularidades respecto a la forma en la cual las personas jóvenes se relacionan con los elementos políticos del proceso 
de campaña electoral, desde la ausencia o presencia de estos, como vimos en la primera categoría, cabe resaltar las similitudes en cuanto a la manera de elaborar la imagen del o la "joven" con la política.

\section{Jóvenes como preparación, relevo o futuro}

Una de las figuras más recurrentes en las conversaciones sobre las personas jóvenes es cuando aparecen en proceso de preparación, como relevo o como futuro. Estos elementos quedan ejemplificados en el siguiente extracto con la valoración que hace una colaboradora militante de 36 años:

-Como en que... Involucrarlos más, no sé, como fiscales, como miembros de mesa, involucrarlos en las actividades, involucrarlos para que sepan que ellos también son importantes porque, di, lamentablemente los viejos ya van para viejos, entonces necesitamos la gente joven que va a ser el futuro del partido, entonces necesitamos involucrarlos, que se comprometan para que sean los que, desde antes prepararlos para futuros diputados, presidentes, ministros, o sea... Hay que prepararlos desde ya, que se involucren precisamente para tener a gente realmente preparada para gobernar en un par de décadas más (Observador 1, comunicación personal, 25 de enero del 2018).

Este extracto resulta significativo, pues ella misma en esa conversación se posiciona fuera de la participación de la juventud del partido - que delimita entre los 18 a los 35 años-. Pero, además, porque proyecta la importancia de la participación de este sector a futuro, en un presente de preparación que lo asegure. Este tipo de narraciones se repiten en Montes de Oca, esta vez por parte de un señor de 58 años colaborador del mismo partido:

Aproveché para preguntarle cómo veía él a los jóvenes dentro del partido, qué papel creía que tenían. Respondió que para él eran importantes porque representaban un "relevo", que eran quienes iban a conducir al partido "en el futuro", aunque, desde su punto de vista, "tienen que aprender mucho todavía", "comprometerse más" y "ser 
más serios" (Observador 2, comunicación personal, 17 de enero del 2018).

Como mencionamos, este tipo de posiciones no son exclusivas de personas por encima de un cierto rango etario, son parte de la realidad en la que interactúan también aquellas consideradas jóvenes, como vemos en una conversación con dos personas entre 23 y 26 años:

Les pregunto qué marca la diferencia en términos de ese lugar diferente que ellos consideran el partido le da a la juventud. Andrea responde que el partido "ha sabido integrar a los jóvenes sin pelearse con los adultos", y cree que ha sido así porque ambos sectores generacionales han ido entendiendo el papel y los tiempos que corresponden a cada uno, es decir, que la juventud ha entendido que "hay procesos y tiempos para relevos", pero también los grupos de personas adultas del partido y que están al frente de los órganos políticos internos más importantes han entendido que "tienen que dar lugar a los jóvenes", y "han valorado todos los aportes que pueden hacer los jóvenes en las campañas y el crecimiento del partido" (Observador 2, comunicación personal, 12 de enero del 2018).

\section{Ni persona ni sujeto político}

Además de las imágenes que presentan a los jóvenes "en proceso de", otras hacen énfasis en supuestos relacionados con la incapacidad de los jóvenes y toda una serie de calificativos que los anulan como personas o, si se quiere, como sujetos políticos. Como vemos en una conversación de unas adultas mayores:

La señora dice que con solo verlo [al candidato] se nota, que ella lo ve "muy güila", que se ve que no tiene experiencia, que se ve "muy blandito". Ella considera que la mejor opción en estas elecciones son otros candidatos, porque son los que "tienen mano dura y más valores morales y de familia" [...] Una de ellas replica: "para gobernar se ocupa un hombre de mano dura y experiencia, no carajillos que no saben ni dónde están parados, miando fuera del tarro"7 (Observador 2, comunicación personal, 8 de diciembre del 2017).

7. Expresión popular para hacer referencia a una persona o grupo de personas que no saben lo que están haciendo.

Esta forma de anular a los jóvenes como personas y sujetos políticos no solo lo vemos en los discursos que se usan para referirse a ellos, sino también en términos prácticos. Como mencionamos anteriormente, en Montes de Oca se 
organizó un debate por parte de un colectivo conformado por sectores de personas jóvenes de diversas instancias, el cual fue promocionado como un espacio para escuchar a esta población, pero en términos prácticos no adoptó esta forma:

Esta actividad, en términos generales, no fue ni un de-

bate ni un conversatorio, pues el rígido formato que se utilizó no permitió interacción alguna del público (más que los aplausos). Si bien, constantemente, las personas organizadoras aludieron a que sería un espacio para que las y los jóvenes expresaran sus puntos de vista, lo cierto es que todo fue muy pautado y controlado. [...] No hubo tampoco ningún intercambio directo entre los candidatos. Al final, fueron ellos [los candidatos] los que marcaron el ritmo y manejaron la discusión (Observador 2, comunicación personal, 6 de diciembre del 2017).

La interacción con las personas jóvenes aparece más como una cuestión nominal. Entablar diálogo, conversación o debate con ellas no es algo que se presentara de forma práctica durante el trabajo de campo.

\section{Ideas jóvenes}

La mayoría de las acciones de las personas jóvenes estaban referidas a actividades instrumentales, o bien a las "ideas jóvenes" que podían aportar. Es decir, aunque el colectivo social que conforman reconoce la importancia de su participación, este es resaltado en tales términos. En actividades secundarias o referidas a las "ideas":

A pesar de ello, Fabián afirma que ha encontrado en el partido no solo amigos y un "sentido" de que puede "aportar algo al país", aunque no necesariamente desde "puestos de poder" o "buscando protagonismo". Andrea interviene para decir que Fabián es un "buen ejemplo" de un buen grupo de jóvenes [del partido] que ella conoce que no están "metidos en el partido para ser políticos", sino porque tienen ciertas convicciones y en el partido encuentran las condiciones para participar "desde un lugar 
que respeta y da valor a las ideas de los jóvenes" (Obser-

vador 2, comunicación personal, 12 de enero del 2018).

Además, las personas que son externas a los partidos perciben como poca e insuficiente la participación de las personas jóvenes en la actualidad, como se refleja en la interacción con un señor de unos 50 años:

Me dice también que somos las personas jóvenes las que deberíamos estar tomando los espacios de representación política, pero que él ve que hay pocos jóvenes participando. Les pregunto por qué piensan esto, si antes veían más jóvenes involucrados con los partidos en las campañas. Me responden que ellos piensan que hace cuatro años se veían más, que hacían más actividades, que ahora "todo se ve muy apagado", "como sin color". Los únicos jóvenes de partidos a los que han visto son los que han pasado a repartir volantes por su casa (Observador 2, comunicación personal, 8 de diciembre del 2018).

\section{Asegurar y ejercer el voto}

Es interesante notar que los señalamientos anteriores, referidos al proceso de campaña política, difieren cuando el análisis se desplaza propiamente al día de las elecciones. En este momento, el entorno en cual se desarrolla el proceso electoral evidencia una sobrerrepresentación de personas consideradas como jóvenes.

En el día de las elecciones, las observaciones en ambos cantones no muestran mayores diferencias entre sí. Hay una preponderancia de participación de las personas consideradas jóvenes sobre todo a nivel de colaboración instrumental. Como guías, ayudantes en los toldos o atrayendo a las personas a votar son parte de las prácticas realizadas. La imagen de las personas sigue apareciendo, pero con mayor recurrencia en función de aspectos relacionados con las ideas, las propuestas o los temas que se suponen son de interés de un "colectivo" marcado por la condición joven, entiéndase etaria.

Para este día, la valoración de la participación de las personas jóvenes está sobre todo en función del voto y la forma en la que pueden aportar, ya sea realizando una elección o procurando convencer a otras personas. Convencer es parte de las prácticas que las personas jóvenes deben desarrollar, 
pero no necesariamente pasa ni por un conocimiento profundo de las propuestas del partido ni por una militancia prolongada en este. Tal como se evidencia en la siguiente conversación con unas mujeres menores de 22 años:

- ¿Y ustedes como desde qué día se organizaron con el partido? ¿Cómo desde hace cuánto?

- Llevan varios días diciéndonos que por favor viniéramos y nos mandaron información.

-Capacitación no tuvimos porque, digamos, yo trabajo.

Se me hace muy complicado y ellas estudian.

-Ajá, nosotras ya entramos al colegio y teníamos que ver todo eso.

—Es más complicado. Pero sí nos mandaron como vídeos para informarnos (Observador 1, comunicación personal, 4 de febrero del 2018).

Finalmente, cabe señalar que las personas jóvenes no solo aparecen en los registros de campo en términos de quienes deben convencer a otras, sino también como aquellas que solicitan ser convencidas, este es el caso de un hombre de 25 años:

— ¿Por qué está indeciso?

- Yo no pensaba ir a votar. Pero hay que hacerlo, hay que hacerlo, es un derecho y un deber. La vez pasada voté por el Frente Amplio, pero ya no, solo estoy seguro de que por ese no. Está difícil, está difícil. Por alguno de los otros voy a votar, no sé por quién, ja, ja, ja. Hay que salir a votar, hay países en los que no se puede hacer. Es un derecho y un deber (Observador 1, comunicación personal, 4 febrero del 2018).

Es importante en este extracto representativo de otras imágenes, el hecho de que las personas mostraban un convencimiento en cuanto al ejercicio del 
voto, pero constantemente resaltan una solicitud de ser convencidos de por quién deben o no votar.

\section{Para concluir: prácticas de la juventud en la participación política}

Los hallazgos presentados con anterioridad deben ser leídos en conjunto para dar una idea integrada de cómo podemos comprender la forma en la cual las personas, que son consideradas socialmente como jóvenes, se relacionan con la política; esto, a pesar de que la información se presente dividida en tres categorías con fines meramente analíticos: la primera referida al ambiente, la segunda vinculada a la familia como grupo de referencia y, la tercera, relacionada con la imagen en las prácticas.

La primera nos permite señalar que las personas jóvenes no desarrollan sus prácticas en tiempos y espacios homogéneos, más bien el entorno donde se desenvuelven es diferenciado y muta constantemente, en tanto las actividades que realizan no necesariamente están en función del proceso electoral. Es decir, sería falso pensar en la existencia de un espacio político de participación previamente dado y que estas personas están abocadas a involucrarse o no.

La segunda nos presenta a las personas consideradas jóvenes no como un grupo de autorreferencia, sobre todo en relación con las formas de negociar el sentido del entorno donde se desenvuelven. Esto es cierto para el proceso de participación político-electoral y algunos de los elementos asociados a este, como lo son los partidos políticos, la campaña, el sufragio o el voto. Las personas con quienes se trabajó, según lo mostrado más arriba, tienen a la familia como referente inmediato en la valoración sobre tales temas. No se debe dejar de lado que, en las elecciones del 2018, precisamente la familia es uno de los elementos de mayor disputa en la monotemática campaña desarrollada.

La tercera nos presenta cómo la imagen de la persona "joven" se constituye o deviene a partir de una constante implicación práctica, que incluye en este entorno diferenciado a las consideradas jóvenes y no jóvenes. No es una imposición o un moldeamiento, es una negociación de lo que ser joven implica tanto en términos discursivos como prácticos; a partir de ahí, interactúan con la "política" como un mundo resguardado y atribuido al ámbito de los adultos.

\section{Posibles respuestas: investigaciones sobre participación juvenil}

Llegados a este punto, debemos plantearnos cómo se reponden las tres preguntas sugeridas en la introducción del artículo: ¿qué prácticas distinguen las formas de participación de las personas jóvenes durante el proceso? ¿Cómo pueden entenderse dichas prácticas en función del entorno en el cual se desenvuelven? ¿Qué propiedades de este entorno motivan sus formas específicas de participación? 
La literatura que puede ser consultada para comprender la forma como las personas consideradas jóvenes se relacionan con la política -a través de la participación tanto formal como no formal- o su valoración acerca de elementos relacionados con la democracia — percepción, valores democráticos - es relativamente poca. Para el caso costarricense, las investigaciones publicadas son escasas y se reducen a unos cuantos artículos en poblaciones cautivas, en las se puede suponer de previo su involucramiento con la política. Por ejemplo: jóvenes universitarios, miembros de espacios exclusivos de participación -comités cantonales de la persona joven- o estudiantes de colegios (Vega 1992; Rodríguez y Castro 2003; Franceschi y Chaves 2014; Morales-Ramírez, Castro-Pérez y Bolaños-Mora 2015).

Lo anterior también es cierto para trabajos en otros países como Colombia, Chile, Venezuela y México (Lozano Ardila 2008; Tabares 2013; Díaz Gómez y Salamanca Aragón 2012; Sandoval Moya y Hatibovic Díaz 2010; Carrasco Azzini 2010; Murga Frassinetti 2009). En la mayoría de referencias, la población con la que se trabaja es universitaria, o bien forman parte de colectivos que tienen luchas políticas claras -ecologistas, vegetarianistas, feministas, antimilitaristas- (Tabares 2013).

De estos trabajos, es posible extrapolar algunas ideas para la participación de población estudiantil o miembros de instancias específicas únicamente. Pero, por un lado, no se puede asumir que las prácticas y nociones de estas poblaciones cautivas reflejen las formas de participación política de "las personas jóvenes" en general.

Por otro lado, se emplean diversos conceptos para dar cuenta de estas prácticas políticas, supuestamente diferenciadas, de quienes son nombrados prescriptivamente como jóvenes. Tales como subjetividad política (Lozano Ardila 2008), cultura política (Vega 1992; Rodríguez y Castro 2003; Murga Frassinetti 2009; Tabares 2013; Treminio y Pignataro 2015) y socialización política (Sandoval Moya y Hatibovic Díaz 2010).

Lo anterior respondería a las preguntas de este artículo a partir de una sensibilidad especial, de una valoración diferenciada o de un proceso de socialización específico. Es decir, las prácticas, acciones y valoraciones políticas de las personas jóvenes serían propias en tanto quienes las ejecutan son jóvenes, quienes viven una supuesta condición particular de esta población.

Para el caso costarricense, Treminio y Pignataro, para las elecciones generales 2014, ensayaron la posibilidad de identificar a "los jóvenes", de 18 a 35 años, como una población de interés en la ciencia política. Apelaban a la diferencia en las formas de comportamiento y pensamiento, la cual se condensa bajo la supuesta existencia de una "cultura política de los jóvenes costarricenses" $(2015,42)$. No hay una definición clara en el texto, pero que se puede deducir la identifican como "valores, percepciones y actitudes hacia el sistema político" $(2015,42)$.

A pesar de lo que presentan como evidente en los datos, al reflexionar, no se detecta soporte a lo que quieren comprobar: la diferenciación entre jóvenes y 
no jóvenes. En su defecto, esta es más bien marginal. La crítica que presentamos a la interpretación surge precisamente de la imposibilidad de comprobar tal diferencia a nivel fáctico.

\section{Alternativa a la comprensión de la participación juvenil}

De la literatura anterior, se deducen tres discusiones posibles. La primera, tiene que ver con los lugares y las poblaciones a partir de las que se teorizan las particularidades de la participación política juvenil. La segunda, se relaciona con la forma prescriptiva y autorreferencial que adoptan dichos modos particulares de participación reflejada en la idea de cultura política juvenil. La tercera, y superadas estas dos posiciones, cuál sería la alternativa según lo observado en el trabajo de campo.

La información analizada en esta investigación nos permite plantear que, para evitar un sesgo del sobreviviente, debe entenderse esta población en términos de cómo emergen en un entorno en constante cambio. No limitarnos a las poblaciones cautivas, dado que lleva a expresar aspectos que parecen inherentes a su condición juvenil, ya sea por deseabilidad social o por las actividades que los convocan. Pero, además, permite reconocer que en los entornos donde se desarrollan están en juego constantes negociaciones con no-jóvenes respecto a las condiciones de posibilidad en las que pueden expresarse.

De lo anterior, se sigue el segundo punto de no autorreferencialidad, debido a las múltiples pertenencias de las personas jóvenes, que participan de distintos lugares con otras no-jóvenes, como la familia. No tendría sentido hablar de una socialización o una cultura particular, toda vez que estas personas, al menos en lo observado en el proceso electoral, median sus formas de participación junto con otros grupos.

Finalmente, vemos que es a través de las condiciones de posibilidad evidenciadas en las prácticas, como forma de expresar la condición joven, en las cuales se hace patente la especificidad de la participación, entendidda solo en ese entorno y en esas referencias a otras personas no jóvenes. Las prácticas de la juventud en la participación política quedan relegadas a nivel de ideas y de las condiciones de posibilidad dispuestas para dichos efectos. Esto significa la preparación para el relevo, su anulación como sujeto político, el aporte desde las ideas, como votante y mano de obra en la consecución de votos, ello coincide con los resultados de las ediciones anteriores del OPEJ $(2013,2014,2016)$ citados más arriba, sobre la imagen ambivalente de la persona joven: por un lado, es vista como cambio y, por otro, sin una vinculación más allá de actividades proselitistas, inexpertos, inmaduros e irresponsables. 


\section{Los jóvenes como futuro}

A partir de las observaciones de esta investigación, se demuestra que, en un entorno donde la dimensión relacionada con el proceso de campaña política, las personas jóvenes no aparecen de manera diferenciada según los discursos y las prácticas que desarrollan. En resumen, no hay forma de identificar un colectivo o grupo -en términos etarios- que estructure algo considerado como una cultura política de personas jóvenes costarricenses, a partir de la cual se involucren en procesos de participación.

Lo que resulta claro, en términos del proceso de campaña política, es que las personas consideradas jóvenes no son tomadoras de decisiones, sino ejecutoras de decisiones ya tomadas. Esto último les asegura la posibilidad de preparación, relevo y futuro, lo cual no es exclusivo de este ámbito de su vida; por el contrario, se puede identificar también en muchos otros.

Después del panorama expuesto, una posible respuesta a la interrogante “¿qué quiere decir 'los jóvenes son el futuro', en términos de la participación política durante el proceso de campaña electoral?" es que las personas jóvenes son concebidas desde este ámbito como sujetos inacabados, incapaces de tomar decisiones, algunas veces sobre sí mismos y la mayoría de las veces sobre los demás.

\section{Bibliografía}

Alvarado Chaves, Gustavo. 2014. «Democracia e Institucionalidad: La Visión de Las Juventudes.» Revista Consejo de La Persona Joven, 102-10.

Carrasco Azzini, Giovanni. 2010. «Participación y Tendencias Políticas En Estudiantes Universitarios: El Caso de La Universidad de Chile». Última Década 32: 85-103.

Carrithers, Michael. 1995. ¿Por qué los humanos tenemos culturas? Una aproximación a la antropología y la diversidad social. Madrid: Alianza Editorial.

Díaz de Rada, Ángel. 2012. El taller del etnógrafo. materiales y herramientas de investigación en etnografía. Madrid: UNED. 
Díaz Gómez, Álvaro, y Liliana Salamanca Aragón. 2012. «Los jóvenes son sujetos políticos... a su manera». Utopía y Praxis Latinoamericana 17 (57): 109-17.

Franceschi, Hannia, y María Fernanda Chaves. 2014. «Juventudes rurales y participación: un derecho con asidero real o un interés gubernamental de participación restringida?» Pensamiento Actual 13 (20): 11-24. http://revistas.ucr.ac.cr/index.php/pensamiento-actual/article/view/ 15020\%5Cnhttp://revistas.ucr.ac.cr/index.php/pensamiento-actual/ article/download/15020/14966.

González-Sancho, Roy. 2017. «Revisión Sistemática de Literatura Sobre Comportamiento Político y Juventud En Latinoamérica y Costa Rica Desde 1990 Hasta 2016». Revista Rupturas 7(2): 93-143.

González, Gerardo, Kattia Bermúdez, y Lucía Astorga. 2018. «Gran afluencia de votantes marca la jornada electoral». https://www.nacion.com/elpais/politica/gran-afluencia-de-votantes-marca-la-jornada/ GZBLR3JFVBBS7CVJPSJCATLY4Y/story/

González Sancho, Roy, y Evita Henríquez Cáceres. 2016. «Participación juvenil en espacios formales de deliberación política: entre adultocentrismo y reproducción del discurso adulto». Revista Rupturas 7(1): 125-47. http://0-search.ebscohost.com.biblio.url.edu/login.aspx? direct=true $\& d b=a s x \& A N=120099107 \&$ lang=es\&site=eds-live.

Ingold, Tim. 2015a. «Desde la complementariedad a la obviación: sobre la disolución de los límites entre la antropología social, biológica, arqueología y psicología». Avá. Revista de Antropología 26: 12-51. https://www.redalyc.org/pdf/1690/169046438003.pdf

Ingold, Tim. 2015b. «Conociendo desde adentro: reconfigurando las relaciones entre antropología y la etnografía» . Etnografías contemporáneas 2(2): 218-230. 
Ingold, Tim. 2015c. «Contra el espacio: lugar, movimiento y conocimiento» . Mundos plurales. Revista Latinoamericana de Políticas y Acción Pública 2(2): 9-26.

Ingold, Tim. 2017. «¡Suficiente con la etnografía!». Revista Colombiana de Antropología 53(2): 143-159.

Latour, Bruno. 2008. Reensamblar lo social: una introducción a la teoría del actor-red. Buenos Aires: Manantial.

Lozano Ardila, Martha Cecilia. 2008. «Los procesos de subjetividad y participación política de estudiantes de Psicología de Bogotá». Revista Diversitas-Perspectivas en Psicología 4(2): 345-57. http://www.scielo.org.co/pdf/dpp/v4n2/v4n2a11.pdf.

Mantilla Fernández, Lya De. 1999. «Algunas Aproximaciones a La Participación Política» . Reflexión Política 1(1). http://www.redalyc.org/articulo.oa?id=11010112.

Morales-Ramírez, María, Marianella Castro-Pérez, y Marianela BolañosMora. 2015. «Perspectiva del estudiantado universitario de las diversas carreras de la Universidad Nacional acerca de la democracia en la familia, el centro educativo y el país». Revista Electrónica Educare 19(1): 183-219. http://www.scielo.sa.cr/scielo.php? script=sci_arttext\&pid=S1409-42582015000100011\&lang=pt.

Murillo, Álvaro. 2018a. «Costa Rica elige presidente entre el desencanto y el fervor religioso»

\section{https://www.nytimes.com/es/2018/02/02/espanol/america-latina/costa-} rica-elecciones-presidente-desencanto.html

Murillo, Álvaro. 2018b. «¿Cómo un shock religioso alteró la campaña?» . https://semanariouniversidad.com/pais/shock-religioso-altero-lacampana/

Murga Frassinetti, Antonio. 2009. «La participación política de los estudiantes universitarios en el primer gobierno de alternancia en México.» Región 
y Sociedad 21: 45-63. http://www.scielo.org.mx/scielo.php?pid=S187039252009000200002\&script=sci_arttext.

OPEJ. 2013. «Primera Observación: Elecciones Municipales, Diciembre 2010».

_ 2014. «Comportamiento Político Electoral Juvenil Proceso Electoral 2014». http://www.investiga.uned.ac.cr/agendajoven.

—. 2016. «Observatorio Político Electoral Juvenil: 'Elecciones Municipales 2016'». http://www.investiga.uned.ac.cr/agendajoven.

Rodríguez, Florisabel, y Silvia Castro. 2003. «Centroamérica joven: valores democráticos en la generación de la posguerra.» Ensayos Pedagógicos 2(1): 57-79.

Sandoval Moya, Juan, y Fuad Hatibovic Díaz. 2010. «Socialización política y juventud: el caso de las trayectorias ciudadanas de los estudiantes de la región de Valparaíso.» Última Década 32: 11-36.

Segura Arias, Jorge. 2013. «Gobiernos locales y participación de las personas jóvenes en puestos de elección popular en Costa Rica , 2010». Revista Tribunal Supremo de Elecciones15: 161-75.

Tabares, Catalina. 2013. «Los jóvenes y sus discursos reconfiguradores de la política. acciones políticas con las que resisten la cultura política tradicional». Estudios Políticos (Medellín) 42: 138-56. http://biblat.noip.org/revista/estudios-politicos-medellin/articulo/los-jovenes-y-susdiscursos-reconfiguradores-de-la-politica-acciones-politicas-con-lasque-resisten-la-cultura-politica-tradicional.

Téllez, Anastasia. 2007. La Investigación Antropológica. Alicante: ECU.

Treminio, Ilka, y Adrián Pignataro. 2015. «Jóvenes y democracia: comportamiento electoral y actitudes políticas en Costa Rica» Derecho Electoral, 20: 309-343. 
Vega, Mylena. 1992. «Cultura política y legitimidad. Encuesta de opinión entre estudiantes avanzados de la sede central de la Universidad de Costa Rica». Anuario de Estudios Centroamericanos 18(2): 71-90.

Zúñiga Núñez, Mario. 2016. «Practicar la juventud en la Centroamérica contemporánea: una propuesta». Lección Inaugural Sede del Atlántico de la Universidad de Costa Rica. 